Дакі О.А., Ткаченко В.В., Левченко О.В., Кущ О.В.

\title{
ДОСЛІДЖЕННЯ ПРОЦЕСІВ ВІБРАЦІЇ В МАШИННИХ ВІДДІЛЕННЯХ ТЕПЛОХОДІВ
}

Суднобудування у світі є галуззю, яка досить динамічно розвивається з високою капіталізацією. Слід зауважити, щчо ие не лише прибуткове виробництво, а ще й наукоємне. Для будівництва суден використовуються новітні наукові методи у сфері матеріалознавства, навігащіï, енергетичних установок. Відомо, щзо вібрачї та удари супроводжують роботу багатьох машин $i$ механізмів, знижуючи їх надійність $i$ довговічність, а також шкідливо впливають на здоров'я людини. Серйозна ситуація у сфері захисту від вібраџій склалася на засобах водного транспорту.

Розвиток сучасних суднових енергетичних установок пов'язаний, з одного боку, зі збільшенням потужності механізмів, які $\epsilon$ в багатьох випадках джерелами інтенсивного шуму $і$ вібрацій, з іншого боку - значними масштабами використання точних приладів і апаратури різного призначення, чуттєвих до вібрацій.

Таким чином, віброзахист становить значний інтерес як для суднобудівників, так $i$ для фахівиів із суднових енергетичних установок, оскільки вібрація суднового корпусу $i$ його окремих елементів може викликати в корпусі судна появу втомних тріщин, порушити нормальну роботу суднової апаратури і різних вимірювальних приладів, установлених на борту судна, створити негативні умови для перебування пасажирів $i$ членів екіпажу на борту протягом порівняно тривалого часу.

На даний момент питання зниження вібрації займає визначене місце в теорії $i$ практиці суднобудування. Усі судна проходять перевірку вібраційної $i$ шумової активності. Увага приділяється системам зниження активності джерел вібрації $i$ шуму. Крім того, методи проектування передбачають істотне зниження вібрації вже на стадії технічного завдання за рахунок спеціального розташування приміщень щодо джерел вібрації $і$ шуму, раціонального вибору конструкції корпуса, товщини листів обшивки, тощуо.

Значний науковий інтерес представляють собою методи розрахунку вібраційних сил та моментів для розроблення обтрунтованих рекомендацій щодо зміни в конструкиії суден для отримання прийнятних показників. Також важливим завданням є розробка критеріїв оиінювання віброзахисту суден, які можна використовувати як при суднобудуванні, так і при виконанні заходів з модернізачії існуючого флоту.

Конструктивне вдосконалення пружних систем, щз веде до зменшення вібронавантажень корпусу судна $\epsilon$ достатньо важливим науковим напрямком, розвиток якого відповідає розвитку сучасних поглядів на суднобудування. Проектування пружних систем суднових енергетичних установок $\epsilon$ досить трудомісткою задачею і вимагає визначеного ступеня автоматизачї розрахунків. При проектуванні транспортних суден з головними малооборотними дизелями варто враховувати такі особливості, як їх неврівноваженість та компонування, а також взаємодію з корпусними конструкиіями.

Ключові слова: вібрачія, механіка твердого тіла, пружні системи, суднобудування, суднові двигуни. 
Постановка проблеми. Зростання розмірів суден і потужностей силових установок наприкінці XX-го століття, підвищення швидкості суден, особливо контейнеровозів, використання економічних малообертних дизелів (МОД) великої потужності в якості головних двигунів (ГД) призвело до проблем, викликаних підвищенням рівня вібрації, що проявляються у вигляді:

- втомних тріщин у суднових корпусних конструкціях;

- пошкоджень механізмів, пристроїв і елементів гребних установок у машинних відділеннях;

- підвищеного рівня вібрації в надбудовах.

Все це вказує на недостатній рівень вібростійкості пружних систем суднових енергетичних установок і на необхідність нових підходів до конструювання цих систем. Підвищений рівень вібрації проявляється в надбудовах, особливо при резонансах у коливаннях основної пружної системи допоміжних дизелів, і в кормовій частині суден, де пружні системи піддаються впливові двох джерел: головних МОД і гребних гвинтів (ГГ).

Тому очевидною $\epsilon$ актуальність досліджень у напрямку дослідження вібростійкості пружних систем суднових енергетичних установок (СЕУ) i конструктивному вдосконаленню цих систем у цілому та їх окремих елементах зокрема.

Аналіз останніх досліджень і публікацій. Суднова вібрація, яка породжується ГГ і головними дизелями завжди викликала проблеми, що виявлялися у виді втомних тріщин у суднових конструкціях або в елементах гребних установок, підвищеного рівня вібрації механізмів і пристроїв у машинних і румпельних відділеннях.

Виконувалися роботи, присвячені дослідженням вібрації від МОД представниками класифікаційних суспільств, наприклад, Бюро Веритас [1], Норвезького Веритас [2], а також фірмами IHI [3] і MAN B\&W [4].

У цілому цим проблемам присвячені роботи 3 дослідження вібрації на суднах ученими, серед яких Бєлов І.М., Вороня Е.Я., Давидов В.В., Сфремов Л.В., Іванюта Е.І., Гачків Ю.С., Лукаш Э.П., Маттес Н.В., Нікольский Ю.А., Палій О.М., Постнов В.А., Ростовцев Д.М., Тарануха Н.А., Сочінський С.В., Тузів Л.В., Чувіковський В.С., Шиманський Ю.А., Щукіна Е.Н., Галь А.Ф., Зінченко В.І., Клюкін І.І., Гачків Ю.С., Нерубенко Г.П., а також іноземними дослідниками: Asmussen I., Bourceau G., Bryndum L., Choi J., Chang J., Garnier H., Fuji K., Fujino R., Jacobsen S., Kim M., Kim S., Laheld P., Larsen O., Mano M., Masson J., Mizuuchi M., Munn H., Nagai M., Ochi Y., Ohtaka K., Okada Y., Shiraki K., Sontvedt T., Stefenson J., Shyu R., Tanida K., Volcy G., Wang W., Yamaguchi T.

Оскільки в основному проблеми вібрації виникають при резонансних коливаннях пружних систем із частотами головних порядків дизелів, у статті наведено аналіз неврівноважених сил і моментів МОД і запропоновані критерії для їх оцінки. Розрахунки неврівноважених моментів МОД можуть виконуватися згідно методикам робіт Істоміна П.А. та Терських В.П.

Метою статті $\epsilon$ вироблення рекомендацій зі зниження рівня вібрації пружних систем суден з головними МОД до допустимих значень. При цьому передбачається використання різних способів впливу на основну пружну систему “днище-дизель" (ДД), як джерело вібрації.

\section{Викладення основного матеріалу дослідження.}

Дослідження вібрації від МОД.

Критерії оцінки неврівноважених моментів дизелів розроблені на основі коефіцієнтів динамічного посилення при резонансах коливань реальних пружних систем, отриманих у результаті досліджень вібрації і норм вібрації. Водночас вважається, що амплітуди змушених коливань (навіть при резонансі) не будуть перевищувати допустимих величин. 
Для суден, які знаходяться в експлуатації, усунення підвищеного рівня вібрації частіше виконується за рахунок конструктивних заходів, наприклад, зміною твердості пружної системи 3 метою підвищення частоти вільних коливань і усунення умов резонансу. Однак, у ряді випадків це вимагає великих матеріальних витрат і приймаються заходи для призначення забороненої зони в роботі ГГ, що простіше i вимагає тільки встановлення діапазону по частоті обертання валопроводу.

Таким чином, відомості про результати досліджень вібрації, наведені в цій статті, підтверджують можливість зниження рівня вібрації в пружних системах у машинних відділеннях (MB) теплоходів різними способами. До того ж, у багатьох випадках цього можна було уникнути шляхом попереднього аналізу пружних систем 3 погляду запобігання резонансних вібраційних умов ще на стадії проектування суден. Однак, це можливо тільки за наявності вимог по нормуванню нижчих частот вільних коливань пружних систем у МВ, заснованих на спектрах неврівноважених сил і моментів головних МОД.

При аналізі спільних коливань головних МОД з конструкціями корпуса судна (днищем МВ) прийняті основні форми коливань даної пружної системи, які наведено на рисунку 1 для системи 3 одним дизелем (система ДД). Ці форми досить добре вивчені і широко використовуються при дослідженнях вібрації суден.

Деяка зміна форм коливань відбувається у зв'язку з нерівномірністю твердості по довжині і ширині днища МB, а також асиметрією самої пружної системи, наприклад через наявність зв'язків верхнього кріплення основ дизелів 3 одного борту. Також впливає на пружну систему розташування дизелів по довжині МВ і ширині для суден з 2-ма машинами. До того ж з'являються зв'язні коливання системи, оскільки центр мас системи не збігається 3 центром мас дизеля, відносно якого визначаються його неврівноважені сили і моменти [5].

Перша форма коливань системи ДД (рисунок 1 б) відповідає першій формі коливань днища МВ як пластини з пучністю в центрі. У центрі мас дизеля, зміщеного в корму на перекритті МВ, маємо переміщення: $z$ та $\varphi_{y}$.

Н - форма коливань наведена на рисунку 1 г), що відповідає другій формі коливань днища MB (з нейтральною віссю в діаметральній площині (ДП) та при бортових пучностях) й поперечних коливаннях остова дизеля як балки-стінки.

$\mathrm{X}$ - форма коливань системи ДД (рисунок 1 в) відповідає більш високій формі коливань днища MB (з діагональною пучністю) та скручування остова дизеля щодо вертикальної осі z 3 лінійними переміщеннями кінців блоку циліндрів у протифазі. Дана форма коливань властива тільки системам ДД із МОД при відносно великій їх висоті і при визначеному порядку роботи циліндрів (значних по величині гармонійних складових горизонтального скручуючого моменту - $M_{x}$ ). Переміщення в центрі мас дизеля: у та $\varphi_{z}$.

$\mathrm{x}$ - форма коливань системи ДД представлена на рисунку 1 д). При цьому блок циліндрів робить поперечні синфазні коливання по кінцях і в протифазі - у центрі. Ця форма характерна для дизелів з числом циліндрів більш 8, у яких досить великі по величині гармонійні складові горизонтального скручуючого моменту від нормальних сил високих порядків та відповідної форми коливань векторними діаграмами.

Аналізуючи системи ДД, ряд дослідників[6-9] наводили залежності частот іi

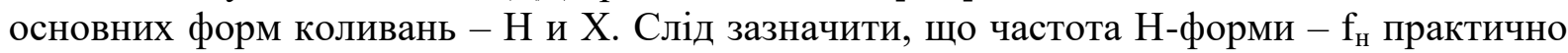
не змінюється зі збільшенням кількості циліндрів для кожної моделі дизеля [7]. Це вірно в тому випадку, якщо розглядати коливання тільки основи дизеля як балкистінки. Однак, збільшення числа циліндрів і маси приводить до підвищення твердості днища MB i, отже, частоти системи ДД. Частота fх значно знижується зі збільшенням довжини дизеля.

Дослідження вібрації від гребних гвинтів. 
Гребний гвинт є джерелом загальної та місцевої вібрації на судні. При цьому розглядається кілька періодичних зусиль і моментів від них, що обумовлені наступними основними причинами:

1) Статичною неврівноваженістю гвинта, тобто розбіжністю центра мас та вісі обертання (відцентрова сила, вертикальна і горизонтальна складові, які змінюються згідно гармонійного закону з частотою першого порядку).

2) Динамічною неврівноваженістю гвинта у випадку, якщо центр мас та центр інерції не в одній точці (момент у площині нормальної до площини диска гвинта 3 частотою першого порядку).

3) Гідродинамічною неврівноваженістю гвинта, що виникає 3 технологічних причин (нерівномірне розташування лопатей, різнокроковість і т.п.) та викликає горизонтальний i вертикальний моменти на гвинті з частотою першого порядку й першій лопатевою частотою (від ексцентриситету упора, вектор якого для чотирьох лопатевого гвинта розташований у верхньому правому квадранті площини диска гвинта).

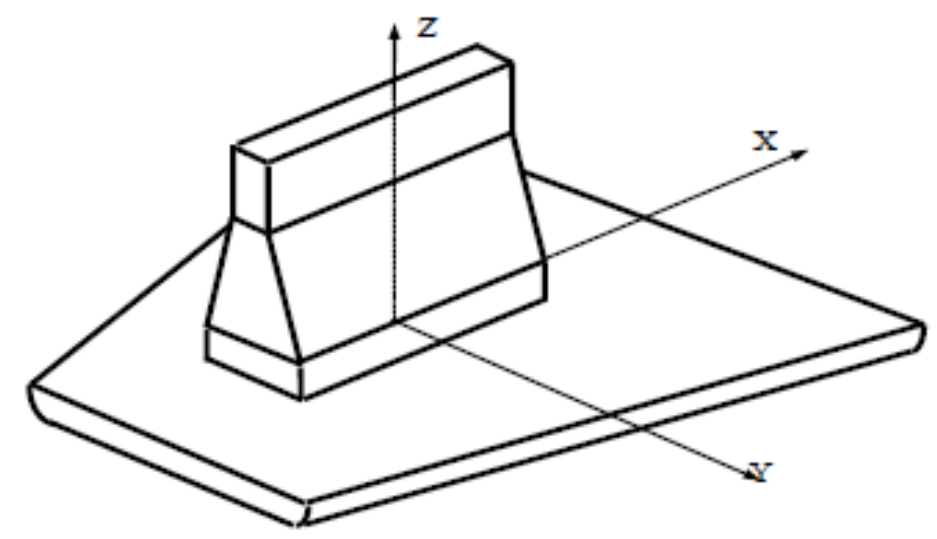

6

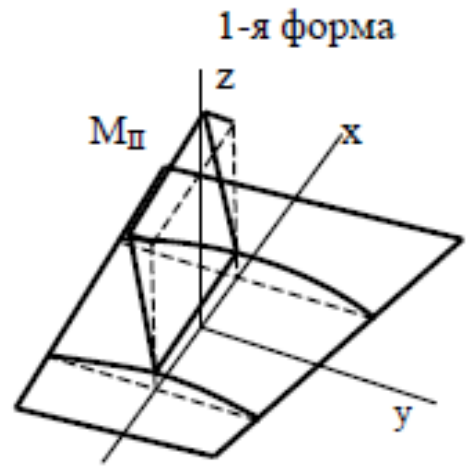

$\Gamma$

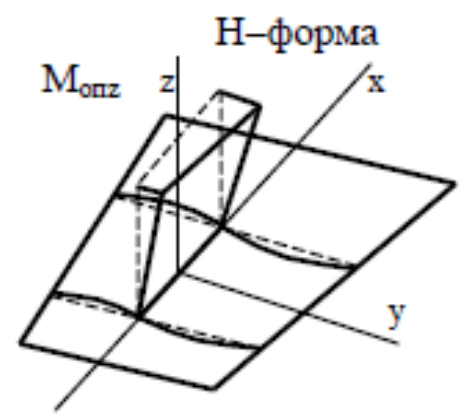

в X-форма

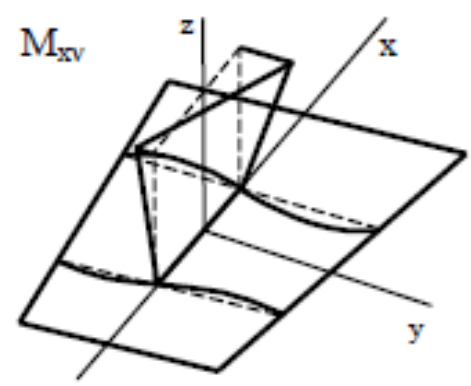

д $\quad \mathrm{x}$-форма

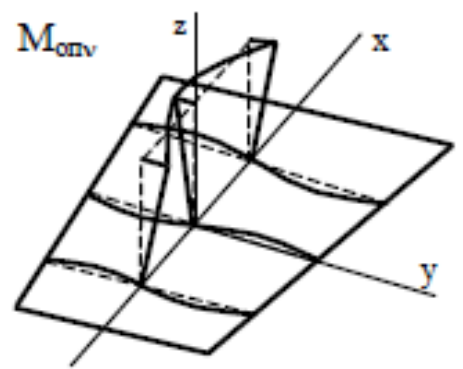

Рисунок 1- Основні форми коливань системи "дизель-днище": a - фізична модель; б - перша форма коливань; в- Н - форма коливань; г - Х - форма коливань; д - х - форма коливань 
4) Пульсацією гідродинамічного тиску, що передається на обшивку днища над гвинтом через воду. Результуюча сила від гідродинамічного тиску, що створює некавітуючим гвинтом, має дві переважні гармонійні складові з 1-й та 2-й лопатевими частотами [11]. Для кавітуючих гвинтів - процес випадковий, у спектрі присутні трохи порівнянних гармонійних складових від першої до п'ятої лопатевих частот [12]. Рівень сумарного тиску, насамперед, залежить від інтенсивності кавітації, що найбільш розвинена при оголенні краю лопатей гвинта і може взагалі зникати при положенні корми на гребені хвилі. При цьому спектр гармонійних складових гідродинамічних тисків змінюється від форми кавітуючого до некавітуючого гвинта, тобто залишається всього дві складові з першої та другої лопатевими частотами.

5) Періодичні сили і моменти від них, які викликаються нерівномірним побіжним потоком у площині диска гвинта, що діють на гребний вал і дейдвудні підшипники (частоти першого порядку, лопатева, подвоєна лопатева і половинна) [12].

Інтенсивність вібрації в будь-якому випадку визначається величинами зусиль, які іiї збурюють, що залежать, в основному, від наступних факторів:

- точності виготовлення ГГ;

- величин зазорів між ГГ і ахтерштевнем;

- кількості лопатей ГГ;

- конструкції ГГ і його параметрів (діаметр, дискове і крокове відношення, форма лопатей);

- форми кормового краю (кілеватості днища в площині диска гвинта, наявності спеціальних пристроїв для вирівнювання потоку і т.п.);

- опади в кормі (ГГ проектуються на положення судна у навантаженому стані), що істотно впливає на виникнення кавітації в баластовому стані суден і при хвилюванні поверхні. Так, наприклад, на судах типу "Варнемюнде" це було підтверджено результатами досліджень вібрації і гідродинамічних тисків. При проектному осіданні Тк $=8,8$ м кавітація була відсутня, спектр гармонійних складових гідродинамічного тиску обмежувався другою лопатевою частотою і з вібрацією проблем не викликало. Однак, при експлуатації цих суден на контейнерних перевезеннях (у Тихоокеанському басейні) із середнім осіданням у кормі - 7,2 м спостерігалася інтенсивна кавітація лопатей гребних гвинтів. При цьому вібрація суднових конструкцій мала частоти від першої до п'ятої лопаті. Це викликало проблеми як з погляду міцності корпусних конструкцій у кормовому краї (у виді утомних тріщин), так і дотримання санітарних норм у приміщення надбудови [4, 10, 12].

У ході натурного експерименту на теплоході типу "Варнемюнде" за вимірами вібрації корпусних конструкцій (КК) і гідродинамічних тисків від гребного гвинта оцінювалися:

- параметри вібрації КК на кормі (амплітуди вібрації, резонансні частоти і порядок коливань);

- рівень гідродинамічних тисків на обшивці днища на тихій воді й хвилюванні (загальний рівень, поле тиску в площинах диска гвинта та у діаметральній площині (ДП)).

Попередні розрахунки пульсації гідродинамічних тисків по методиках [12], не враховували можливе виникнення кавітації на лопатях ГГ та не дали позитивних результатів в оцінці імпульсів. Виміряний тиску декількох точках (у площині диска гвинта і по ДП) на судні істотно перевищував розрахунковий при частоті обертання ГГ вище 0,85 від номінального і досягав величини 0,045 - 0,05 Мпа, що відповідало рівню тиску кавітуючого гвинта [10].

Виходячи зі спектра гармонійних складових гідродинамічного тиску від некавітуючого гвинта, виконується нормування мінімальних частот вільних коливань першої форми, наприклад пластин КК кормового краю: Норвезький Веритас (DnV) 58 
$f_{1} \geq 2,2 \times n \times z$; Російський Морський регістр: $f_{1} \geq 3,0 \times n \times z$; Французьке бюро Веритас (BV): $f_{1} \geq 5,0 \times n \times z$. Де $f_{1}$ - частота першої форми вільних коливань пластини; $n$ - частота обертання ГГ; $z$ - кількість лопатей ГГ. Постійний коефіцієнт у нормах DnV враховує резонансну зону 20\%, що зовсім недостатньо. У нормах МРC частоти вільних коливань пластин повинні в 1,5 рази (для ребер жорсткості - у 1,3 рази) перевищувати частоту збуджуючих сил, тобто другу лопатеву частоту. Тому коефіцієнт значно більше і враховує дефекти пластин та корозійний знос. У Правилах BV вимоги більш жорсткі у відношенні кавітації ГГ, але й це дає гарантію по відношенню до втомної міцності КК у кормі судів, хоча при цьому КК повинні мати значні товщини, що збільшує вагу конструкції корми.

Також необхідно враховувати той факт, що кавітація лопатей ГГ на хвилюванні мінлива, як відзначалося вище, і процес пульсації гідродинамічного тиску має випадковий характер, що добре корелює із заглибленістю гвинта (залежить від положення корми щодо профілю хвилі і кільової хитавиці). Аналогічно змінюються гармонійні складові гідродинамічного тиску і, відповідно, вібрація КК та їх елементів 3 частотами від другої до п'ятої лопатевої.

Дослідження вібрації від гребних гвинтів та головних дизелів.

При кормовому розташуванні МВ вібрація від ГГ і головних МОД сумується та у деяких випадках викликає проблеми [14]. Ці питання можуть бути вирішені на стадії проектування судна після вибору типу головного МОД і розрахунку всіх його неврівноважених моментів, оскільки при проектуванні ГГ можливо варіювати його параметрами i числом лопатей. При цьому слід ретельно аналізувати спектри збуджуючих зусиль від головних МОД і ГГ.

Частоти неврівноважених моментів МОД залежать від числа його циліндрів $\mathrm{i}$ порядку роботи циліндрів (неврівноважені моменти від сил інерції першого та другого порядків $\mathrm{M}_{\mathrm{I}}, \mathrm{M}_{\mathrm{II}}$, гармонійні складові горизонтального скручуваючого момента Мх та перекидаючого моменту) [9].

Частоти збуджуючих зусиль від ГГ залежать від кількості його лопат (лопатеві частоти: перша та друга для некавітуючих гвинтів і більш широкий спектр при кавітації) i балансування (статичний розбаланс виявляється на частоті першого порядку) $[4,5]$.

3 метою виключення збігу частот збуджуючих зусиль від МОД і ГГ необхідно після вибору головного дизеля та аналізу повного спектра його неврівноважених моментів виконати розрахунок двигуна і прийняти число його лопатей. При виборі МОД визначається частота обертання валопроводу та частота першого порядку. Потужність дизеля, необхідна для забезпечення проектної швидкості судна, розраховується виходячи 3 циліндрової потужності конкретної моделі. При цьому агрегатна потужність МОД залежить від числа його циліндрів (від 3 до 14, що спостерігається в даний час у практиці суднобудування).

Несприятливі умови з погляду порушення вібрації від МОД і ГГ були на судах типу "Варнемюнде" [4, 5]. На судні був встановлений головний МОД типу K8Z70/120Е фірми MAN i 4-х лопатевий гвинт. Головний дизель мав порядок роботи циліндрів (1-82-6-4-5-3-7), при якому значення гармонійної складової четвертого порядку $\mathrm{M}_{\mathrm{X} 4}$ горизонтального скручуючого моменту співрозмірне із середнім обертаючим моментом МОД. [12].

Тому для цієї гребної установки збіглися частоти 4-го і 8-го порядків двох пар збуджуючих зусиль:

1) результуючої від гідродинамічних тисків 3 першою лопатевою частотою і $\mathrm{M}_{\mathrm{X} 4}$;

2) результуючих тисків 3 другою лопатевою частотою і гармонійною складової головного восьмого порядку перекидаючого моменту Мопв. 
Це приводило до появи численних втомних тріщин у корпусних конструкціях кормового краю на всіх судах серії і підвищеному рівневі вібрації самого МОД і в надбудові $[4,12]$.

\section{Висновки.}

Числені дослідження вібрації свідчать про те, що пружна система ДД має власні форми i частоти вільних коливань. Збурюючими зусиллями у системі ДД $\epsilon$ неврівноважені моменти МОД. 3 метою запобігання підвищеного рівня вібрації системи ДД (резонансних явищ) необхідно виконувати розрахунки частот вільних коливань основної системи ДД і пружних підсистем, утворених механізмами i пристроями в МВ, на стадії проектування судна. У ряді випадків вимушені коливання системи ДД, особливо при наявності резонансів по одній з форм коливань, викликають проблеми як з погляду втомної міцності деталей МОД і конструкцій у МВ, так і підвищеного рівня вібрації в МО і надбудові.

Спектр збурюючи зусиль від ГГ обмежений другою лопатевою частотою для некавітуючих гвинтів, що повинно враховуватися при проектуванні конструкцій кормового краю суден.

Перспективним напрямком даних досліджень $є$ розробка безпосередніх рекомендацій при проектуванні МВ перспективних проектів суден.

\section{ЛІТЕРАТУРА}

1. An Introduction to Vibration Aspects of Two-Stroke Diesel Engines in Ships. // MAN B\&W Diesel A/S.-2015.-November. - 11 p.

2. Arrangement and Detail Main Engine Top Bracing. №3K-2810-007/ Hyundai \& PRISCO: HHI1854-7S60MC-C.

3. Bourceau, G. Forced Vibration Resonators and Free Vibration of the Hull / G. Bourceau, G. Volcy // Inter. Shipbuild. Progress. - 2016, -V.18. -№203. -P.243-271.- №204. P.275-294.

4. Bryndum, L. and Jacobsen S. "Vibration Aspects of Low-speed Diesels", 9th Marine Propaltion Conference, London, 2007.

5. Chang, J. Dynamic response prediction of rolling stays / J. Chang, W. Wang, R. Shyu, W. Yeih // Journal of the Society of Naval Arhitects and Marine Engineers. -2017.V.16. - №4. -P.51-61.

6. Fuji, K. IHI Ship Vibration Measuring and Analysing System and its Application Results / K. Fuji, Y. Okada // Japan Shipbuilding and Marine Engineering.-2016.V.12.-№1. -P.23-35.

7. Further Development and Application of the MC Engines. - MAN B\&W Diesel A/S, 2017, February. - 23 p.

8. Khoodiakov, S. Analysis of vibration of marine diesel generators with vibroinsulators/ S. Khoodiakov // Proceedings TEAM'2000. -Vladivostok.-2000. - P.517-518

9. Fisher, G. Von HaupmotorerregtsSchiffsschwinungen/ G. Fisher // Schiff und Hafen.2018, -29.-№12. - P.1129-1132.

10. Hoilund, A. Propeller Cavitation as a Sourse of Vibration / A. Hoilund, K. Holden, T. Sontvedt // Schiff und Hafen. -2013.-25.-№7. -P.622-626.

11. Khoodiakov, S. Principles of Laying Down Limits of Elastic System Free Vibration Frequencies in Engine Rooms / S. Khoodiakov // Proceedings ISC'2002. -2002. -P.143150.

12. Ochi, Y. Prevention of Engine Room Vibration and Engine Room Bottom. Report $1 /$ OchiY., K. Tanida, R.Fujii // Ishikawajima-Harima Eng. Rev. -2018.-V.16. №6. P.655-666.

13. Ohtaka, K. Some Comments on the Hull Vibration Induced by Engine / K. Ohtaka // Inter. Symp. Mar. Eng. - Tokyo.-2014. -P.89D-92D. 
14. Худяков, С.А. Практика решения проблем вибрации судовых дизелей: моногр. / С.А. Худяков. - Владивосток: Изд-во Морского государственногоуниверситета, 2016. - 172 c.

\section{REFERENCES}

1. An Introduction to Vibration Aspects of Two-Stroke Diesel Engines in Ships. MAN $B \& W$ Diesel A/S, 2015, November, $11 \mathrm{p}$.

2. Arrangement and Detail Main Engine Top Bracing. №3K-2810-007/ Hyundai \& PRISCO: HHI1854-7S60MC-C.

3. Bourceau, G.and Volcy, G. (2016) "Forced Vibration Resonators and Free Vibration of the Hull", Inter. Shipbuild. Progress, Vol.18,No.203, pp.243-271, No.204, pp.275-294.

4. Bryndum, L. and Jacobsen S. (2007),"Vibration Aspects of Low-speed Diesels", 9th Marine Propaltion Conference, London.

5. Chang, J., Wang,W.,Shyu,R.and Yeih, W. (2017), "Dynamic response prediction of rolling stays", Journal of the Society of Naval Arhitects and Marine Engineers, Vol.16,No.4, pp.51-61.

6. Fuji, K. and Okada Y. (2016), "IHI Ship Vibration Measuring and Analysing System and its Application Results", Japan Shipbuilding and Marine Engineering, Vol.12, No.1, pp.23-35.

7. Further Development and Application of the MC Engines. - MAN B\&W Diesel A/S, 2017, February, 23 p.

8. Khoodiakov, S. (2000),"Analysis of Vibration of Marine Diesel Generators with Vibroinsulators",Proceedings TEAM'2000, pp.517-518.

9. Fisher, G. (2018), "Von HaupmotorerregtsSchiffsschwinungen", Schiff und Hafen, 29, No.12, pp.1129-1132.

10. Hoilund, A., Holden,K.andSontvedt T. (2013), "Propeller Cavitation as a Sourse of Vibration", Schiff und Hafen, 25, No7, pp.622-626.

11. Khoodiakov, S. (2002), "Principles of Laying Down Limits of Elastic System Free Vibration Frequencies in Engine Rooms", Proceedings ISC'2002, pp.143-150.

12. Ochi, Y., TanidaK.andFujii, R. (2018), "Prevention of Engine Room Vibration and Engine Room Bottom. Report 1"Ishikawajima-Harima Eng. Rev, Vol.16, No.6, pp.655666.

13. Ohtaka, K. (2014), "Some Comments on the Hull Vibration Induced by Engine"Inter. Symp. Mar. Eng., pp.89D-92D.

14. Khudyakov, S.A. (2016), "Praktikaresheniyaproblemvibratsiisudovykhdizelei: monografiya" [The practice of solving the problems of vibration of marine diesel engines: monograph.],Izd-voMorskogogosudarstvennogouniversiteta, Vladivostok, $172 \mathrm{p}$.

\section{Даки Е.А., Ткаченко В.В., Левченко О.В. \\ ИССЛЕДОВАНИЕ ПРОЦЕССОВ ВИБРАЦИИ В МАШИННЫХ ОТДЕЛЕНИЯХ ТЕПЛОХОДОВ}

Судостроение в мире является отраслью, которая достаточно динамично развивается с высокой капитализацией. Следует отметить, что это не только ценное производство, но и наукоемкое. При строительстве судов используются новейшие научные методы в сфере материаловедения, навигачии, энергетических установок. Известно, что вибрации и удары сопровождают работу многих машин и механизмов, снижая их надежность и долговечность, а также вредно влияют на здоровье человека. Особенно серьезная ситуация в области защиты от вибраций сложсилась на судах водного транспорта. 
Развитие современных судовых энергетических установок связано, с одной стороны, с увеличением мощности механизмов, которые есть во многих случаях источниками интенсивного шума и вибрачий, с другой стороны - значительными масштабами использования точных приборов и аппаратуры различного назначения, чувствительных к вибрации.

Таким образом, виброзащита представляет значительный интерес как для судостроителей, так и для специалистов по судовым энергетическим установкам, так как вибрачия судового корпуса и его отдельных элементов может вызвать в корпусе судна появление усталостных трещин, нарушить нормальную работу судовой аппаратуры и различных измерительных приборов, установленных на борту судна, создать негативные условия для пребывания пассажсиров и членов экипажа на борту в течение сравнительно длительного времени.

В настоящее время вопрос снижения вибрации занимает определенное место в науке и практике судостроения. Все суда проходят проверку вибрационной и шумовой активности. Внимание уделяется системам снижения активности источников вибрачии и иума. Кроме того, методы проектирования предусматривают существенное снижение вибраџии уже на стадии технического задания за счет специального расположения помещений относительно источников вибрации и шума, рационального выбора конструкиии корпуса, толщины листов обшивки и тому подобное.

Значительный научный интерес представляют собой методы расчета вибрачионных сил и моментов для разработки обоснованных рекомендащий по изменению в конструкиии судов для получения приемлемых показателей. Также важной задачей является разработка критериев оченки виброзащиты судов, которые можно использовать как при судостроении, так и при выполнении мероприятий по модернизачии существующего флота.

Конструктивное усовершенствование упругих систем, что ведет к уменьшению вибронагрузок корпуса судна есть достаточно важным научным направлением, развитие которого соответствует развитию современных представлений о судостроении. Проектирование упругих систем судовых энергетических установок является достаточно трудоемкой задачей $u$ требует определенной степени автоматизации расчетов. При проектировании транспортных судов с главнылми малооборотными дизелями следует учитывать такие особенности, как их неуравновешенность и компоновку, а также взаимодействие $c$ корпусньли конструкциями.

Ключевые слова: вибрация, механика твердого тела, упругие системы, судостроение, судовые двигатели.

\section{O. Daki, V.Tkachenko, O.Levchenko \\ RESEARCH OF VIBRATION PROCESSES IN MACHINES OF HEAT-MOUNTAINS}

Shipbuilding in the world is an industry that is developing quite dynamically with high capitalization. It should be noted that this is not only a valuable production, but also knowledge-intensive. During the construction of ships using the latest scientific methods in the field of materials science, navigation, power plants. It is known that vibration and shock accompany the work of many machines and mechanisms, reducing their reliability and durability, and also adversely affect human health. A particularly serious situation in the field of vibration protection has developed on watercraft.

The development of modern ship power plants is associated, on the one hand, with an increase in the power of mechanisms, which in many cases are sources of intense noise and vibration, and on the other hand, with the significant use of precision instruments and apparatuses for various purposes, sensitive to vibration. 
Thus, vibration protection is of considerable interest both to shipbuilders and to specialists in marine power plants, since vibration of the ship's hull and its individual elements can cause fatigue cracks in the ship's hull, disrupt the normal operation of ship equipment and various measuring instruments installed on board the vessel, create negative conditions for the stay of passengers and crew on board for a relatively long time.

Currently, the issue of vibration reduction occupies a certain place in the science and practice of shipbuilding. All vessels are tested for vibration and noise activity. Attention is paid to systems for reducing the activity of vibration and noise sources. In addition, the design methods provide for a significant reduction in vibration already at the stage of the specification due to the special location of the premises relative to the sources of vibration and noise, a rational choice of the housing design, the thickness of the sheathing sheets and the like.

Of considerable scientific interest are methods for calculating vibrational forces and moments for the development of reasonable recommendations for changes in the design of ships to obtain acceptable indicators. Another important task is the development of criteria for assessing the vibration protection of ships, which can be used both in shipbuilding and in the implementation of measures to modernize the existing fleet.

Constructive improvement of elastic systems, which leads to a decrease in the vibration load of the hull, is a rather important scientific area, the development of which corresponds to the development of modern ideas about shipbuilding. Designing elastic systems for marine power plants is a rather laborious task and requires a certain degree of automation of calculations. When designing transport vessels with main low-speed diesel engines, one should take into account such features as their imbalance and layout, as well as interaction with hull structures.

Keywords: vibration, solid mechanics, elastic systems, shipbuilding, marine engines. 